\title{
Short Approach toward the Nonracemic A,B,E Tricyclic Core of Calyciphylline B-Type Alkaloids
}

\author{
Patrick Boissarie and Guillaume Bélanger*i] \\ Département de Chimie, Université de Sherbrooke, 2500 boulevard de l'Université, Sherbrooke, Québec J1K 2R1, Canada \\ Supporting Information
}

ABSTRACT: A suitably functionalized tricyclic adduct containing the common A,B,E rings found in calyciphylline B-type alkaloids was obtained in nine linear steps. The key transformation features an efficient one-pot sequence of intramolecular Vilsmeier-Haack cyclization and azomethine ylide 1,3-dipolar cycloaddition in which three cycles, three new carbon-carbon bonds, and three stereocenters are formed, one being fully substituted. This work also demonstrates the first use of a chiral, nonracemic cyclic enol ether as an internal carbon nucleophile.

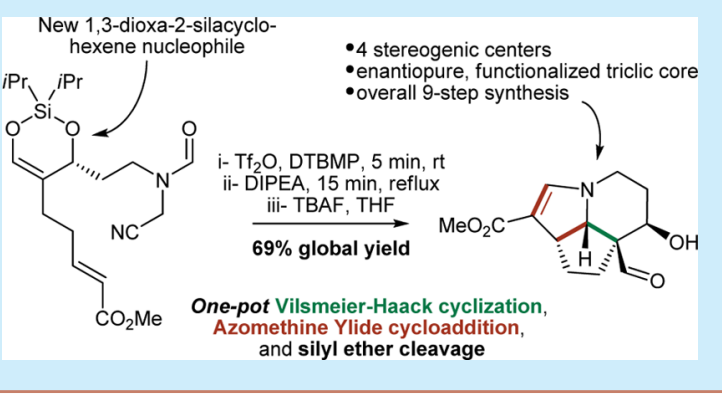

$\mathrm{W}$ ith over 300 structurally distinct structures identified to date, Daphniphyllum form one of the most diverse and unique family of polycyclic alkaloids. Their complex architectures along with their interesting biological activities have attracted attention for many years now, resulting in the development of several elegant and inventive synthetic approaches ${ }^{1}$ triggered in great part by the pioneering work of Heathcock. ${ }^{2}$ In 2003, Morita and Kobayashi isolated calyciphylline $\mathrm{B}$ from the leaves of $\mathrm{D}$. calycinum, presenting a unique hexacyclic core (Figure 1 ). ${ }^{3}$
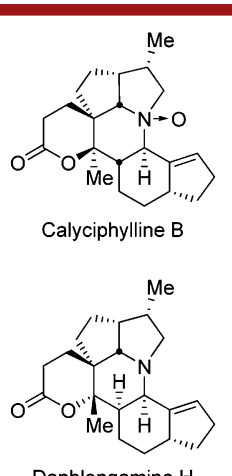

Daphlongamine $\mathrm{H}$
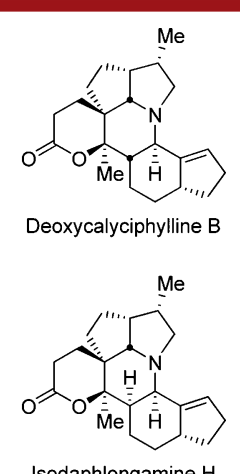

Isodaphlongamine $\mathrm{H}$
Figure 1. Representative calyciphylline B-type alkaloids.

Several other natural products possessing the same skeleton have since been identified. Surprisingly, synthetic efforts toward members of this family remained essentially nonexistent until recent work from the Hanessian group, ${ }^{4}$ ultimately leading to the synthesis of isodaphlongamine $\mathrm{H}^{5}$

We envisaged preparing the tricylic central core 1 of calyciphylline B-type alkaloids using a synthetic strategy developed by our group, ${ }^{6}$ namely, a sequence of intramolecular Vilsmeier-Haack reaction and azomethine ylide cycloaddition (Scheme 1).
Scheme 1. Retrosynthetic Analysis toward the Tricyclic Core of Calyciphylline B-Type Alkaloids
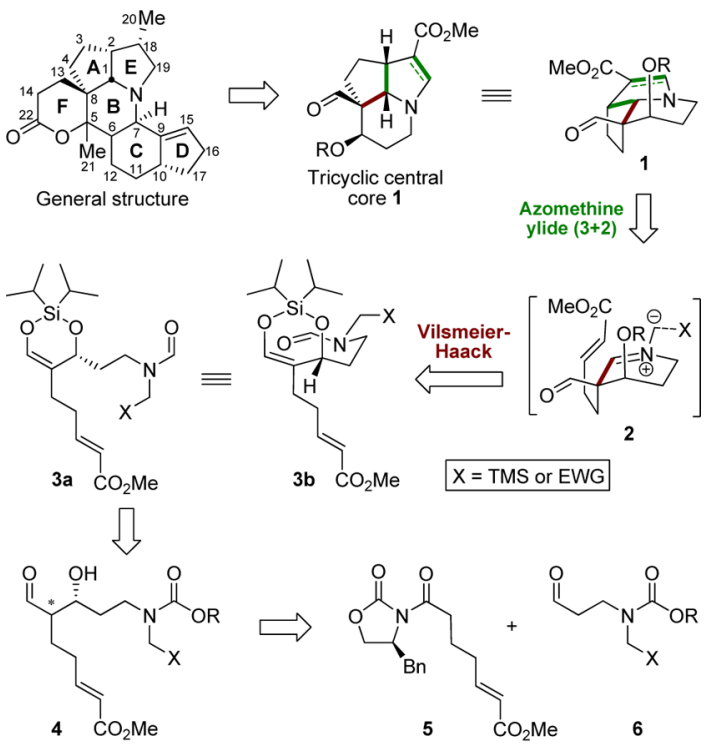

This key step would allow the formation of three of the six rings of calyciphylline B-type general structure in a single transformation. To achieve this sequence in a stereocontrolled fashion, our strategy relies on the use of a chiral cyclic silyl enol ether, namely, a 1,3-dioxa-2-silacyclohexene. The latter would act as the nucleophile in the Vilsmeier-Haack cyclization. The single stereocenter would force the adoption of the only possible reactive chair conformation $\mathbf{3 b}$, locking the dipolarophile chain in the axial position. This specific arrangement would lead to a single diastereomer at $\mathrm{C} 1, \mathrm{C} 2$, and $\mathrm{C} 8$ during the formation of

Received: May 23, 2017

Published: June 30, 2017 
the A, B, and E rings. Azomethine ylide 2 would be generated by desilylation ( $\mathrm{X}=\mathrm{TMS}$ ) or deprotonation ( $\mathrm{X}=$ electronwithdrawing group, EWG) of the corresponding iminium ion, itself obtained from the Vilsmeier-Haack cyclization initiated by activation of formamide 3 . The cyclic silyl enol ether should be obtained from $\beta$-hydroxyaldehyde 4 . However, special attention will be needed when setting reaction conditions to prevent any potential elimination of the hydroxyl group or retro-aldol reaction. Aldehyde 4 would be derived from an Evans aldol reaction between oxazolidinone 5 and aldehyde 6 .

The synthesis of 1,3-dioxa-2-silacyclohexene is poorly documented, $^{7}$ and its use as a carbon-based nucleophile has not been investigated to date. To validate such a nucleophile in the Vilsmeier-Haack cyclization, we synthesized a model substrate lacking the dipolarophile chain that was replaced with a simple methyl group. The synthesis of model substrate 13a started with alkylation of 3-aminopropanol (7) with iodomethyltrimethylsilane and then protection as a carbamate using ethyl chloroformate (Scheme 2).

Scheme 2. Synthesis of Model Substrate 13

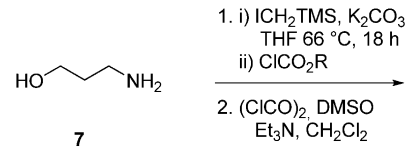
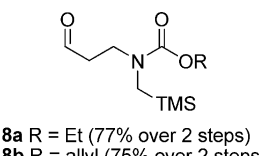

$\mathbf{8 a} R=$ Et $(77 \%$ over 2 steps $)$
$\mathbf{8 b ~ R}=$ allyl $(75 \%$ over 2 steps $)$
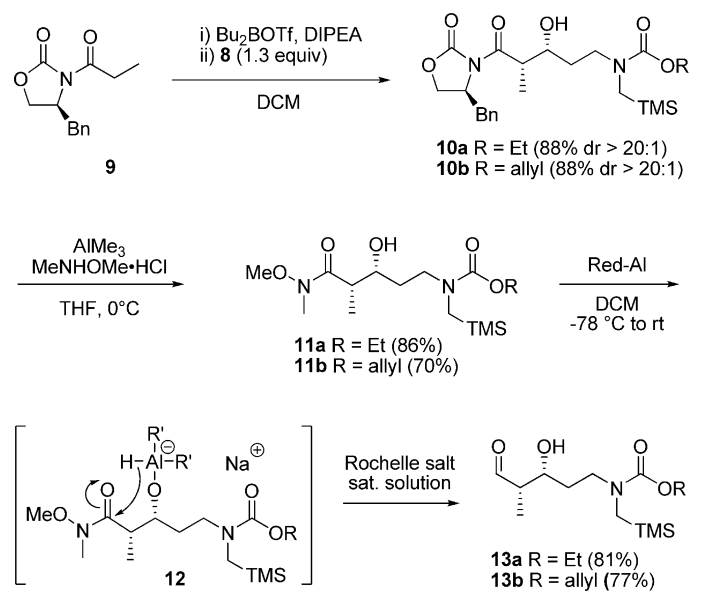

The resulting alcohol was oxidized under Swern conditions to give aldehyde 8a. Evans aldol reaction with oxazolidinone 9 afforded alcohol 10a with good diastereoselectivity. ${ }^{8}$ Transamidation toward Weinreb amide 11a was performed smoothly without affecting the carbamate group. ${ }^{9}$ Standard reduction conditions using DIBAL-H failed to afford aldehyde $13 a{ }^{10}$ We believe that, after a rapid deprotonation of the free alcohol, the resulting $\mathrm{O}-\mathrm{Al}^{i} \mathrm{Bu}_{2}$ complex hinders the amide to a point where reduction with an additional equiv of DIBAL-H can no longer occur. Switching to a reducing agent containing several hydrides was appealing: after the initial deprotonation, an aluminate complex such as $\mathbf{1 2}$ could deliver another hydride intramolecularly to the amide. The proximity of the hydride source to the amide group may become very important on more functionalized substrates bearing the dipolarophile branch to ensure a chemoselective reduction. Unfortunately, $\mathrm{LiAlH}_{4}$ led to poor yields, mainly because of over reduction of the resulting aldehyde. ${ }^{11}$ After a quick survey of reducing agents bearing only the two needed hydrides for initial deprotonation and intra- molecular reduction, we turned our attention toward Red-Al. Gratifyingly, aldehyde 13a was obtained in high yield. ${ }^{12}$

At this point, we were ready to install the 1,3-dioxa-2silacyclohexene as the chiral nucleophile needed in the first step of the key reaction sequence, namely, the Vilsmeier-Haack cyclization. We chose dialkylsilyl bis(trifluoromethanesulfonate) reagents as they are commercially available and possess a good Lewis acidity. Indeed, after silylation of the free alcohol 13a, we expected the resulting silicon monotriflate to act as an internal Lewis acid to promote enolization of the aldehyde in the desired geometry. Although di-tert-butylsilyl ditriflate led to no conversion (Table 1, entry 1), the less bulky diisopropyl

Table 1. Preparation of the 1,3-Dioxa-2-silacyclohexene
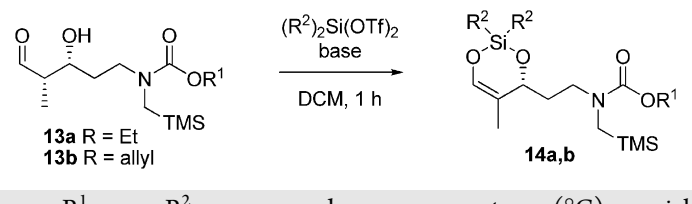

\begin{tabular}{llllcc} 
entry & $\mathrm{R}^{1}$ & $\mathrm{R}^{2}$ & \multicolumn{1}{c}{ base } & temp $\left({ }^{\circ} \mathrm{C}\right)$ & yield $(\%)$ \\
1 & $\mathrm{Et}$ & $t$-Bu & DIPEA & $\mathrm{rt}$ & 0 \\
2 & $\mathrm{Et}$ & $i$-Pr & DIPEA & $\mathrm{rt}$ & 17 \\
3 & $\mathrm{Et}$ & $i$-Pr & DIPEA & -40 & 51 \\
4 & $\mathrm{Et}$ & $i$-Pr & DIPEA & -78 & 25 \\
5 & $\mathrm{Et}$ & $i$-Pr & none & -40 & 0 \\
6 & $\mathrm{Et}$ & $i$-Pr & LDA & -40 & 0 \\
7 & $\mathrm{Et}$ & $i$-Pr & Et ${ }_{3} \mathrm{~N}$ & -40 & 32 \\
8 & $\mathrm{Et}$ & $i$-Pr & 2,6-lutidine & -40 & 22 \\
9 & $\mathrm{Et}$ & $i$-Pr & DIPEA, DMAP & -40 & 27 \\
10 & all & $i$-Pr & DIPEA & -40 & 47 \\
$11^{a}$ & all & $i$-Pr & DIPEA & -40 & 72
\end{tabular}

${ }^{a}$ From anti substrate 16 (cf. $13 b, \beta-M e$ ).

equivalent furnished the expected silyl enol ether 14a, albeit in poor yield (entry 2). Significant improvement was obtained when the reaction was run at $-40{ }^{\circ} \mathrm{C}$ (entry 3). Lower temperature resulted in a slower reaction without any significant yield improvement (entry 4). Further investigation revealed that the base was required (entry 5). However, a strong base appeared to be too reactive (entry 6) and led to decomposition. DIPEA was the most suitable base (entry 4 ) as it led to yields higher than those of triethylamine or 2,6-lutidine (entries 7 and 8 , respectively). The use of a pyridine catalyst (DMAP, entry 9) had no significant effect on the outcome of the reaction.

From the perspective of using the synthetic route described in Scheme 2 to access a substrate bearing the dipolarophile branch, we foresaw compatibility issues for the eventual ethyl carbamate cleavage. For this reason, we also tested the allyl carbamate as the nitrogen protecting group. ${ }^{13,14}$ The synthesis of allyl carbamate $13 b$ uneventfully followed the sequence described in Scheme 2. The corresponding 1,3-dioxa-2-silacyclohexene 14b was obtained in approximately the same yield as that for product 13a (Table 1, entries 3 and 10). A side product observed in all these silylation conditions was the corresponding unsaturated aldehyde 15, arising from the elimination of the alcohol on substrate 13 (Scheme 3). A conformational analysis brought some insight on this side reaction. Indeed, when the syn substrate 13 is subjected to silylation, the O-silylated alcohol is presumed to intramolecularly activate the aldehyde as a six-membered ring complex. Two chairlike conformations are then possible: the top conformation exposes a severe steric interaction between the carbamate side chain $(\mathrm{R})$ and one of the isopropyl on silicon, 
Scheme 3. Effect of Relative Configuration on the Formation of 1,3-Dioxa-2-silacyclohexene 14

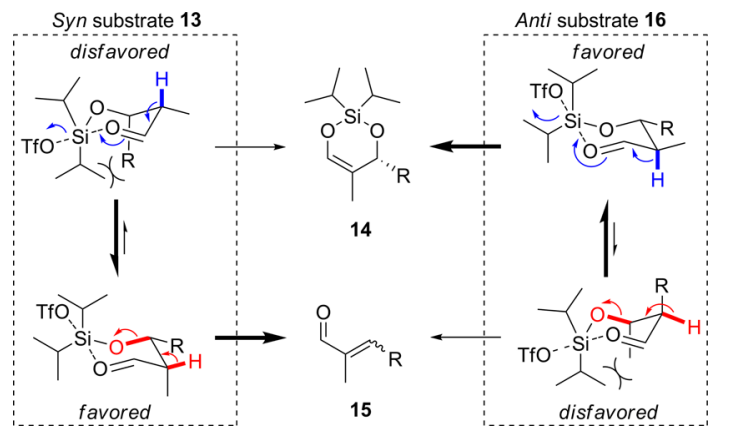

thus favoring the bottom conformation. The latter has no proper alignment to allow enolization of the aldehyde, leading mainly to elimination product 15 . When the same rationale was applied to a substrate 16 presenting an anti relationship between the carbamate side chain $(\mathrm{R})$ and the methyl in the six-membered ring complex, the top conformation should be favored. The latter is perfectly suited for enolization of the aldehyde, and the desired 1,3-dioxa-2-silacyclohexene $\mathbf{1 4}$ should now be favored. This was confirmed by preparing anti substrate $\mathbf{1 6},{ }^{15,16}$ and as expected, a remarkable yield increase was observed (Table 1, entry 11).

Having developed the chemoselective Weinreb amide reduction and the successful preparation of the sensitive 1,3dioxa-2-silacyclohexene moiety, we were ready to synthesize the key cyclization precursor 25 (Scheme 4). A cross-metathesis performed on compound $17^{17}$ with methyl acrylate led to the unsaturated ester 5 . $^{18}$ The latter was then submitted to Heathcock aldol conditions with aldehyde $\mathbf{1 8}$ to afford the anti product 19 in $75 \%$ yield $(97 \%$ based on recovered starting

Scheme 4. Synthesis of Key Step Precursor 24

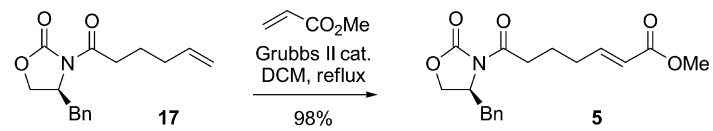

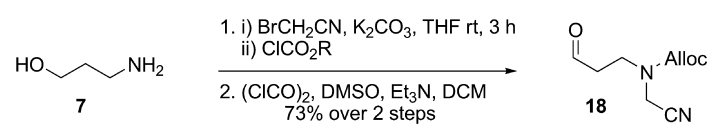

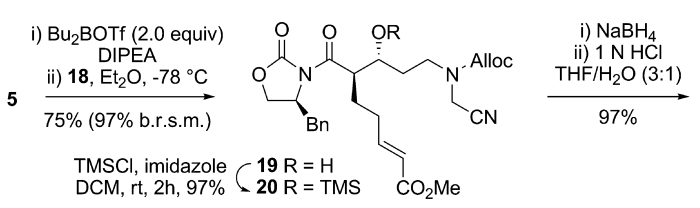
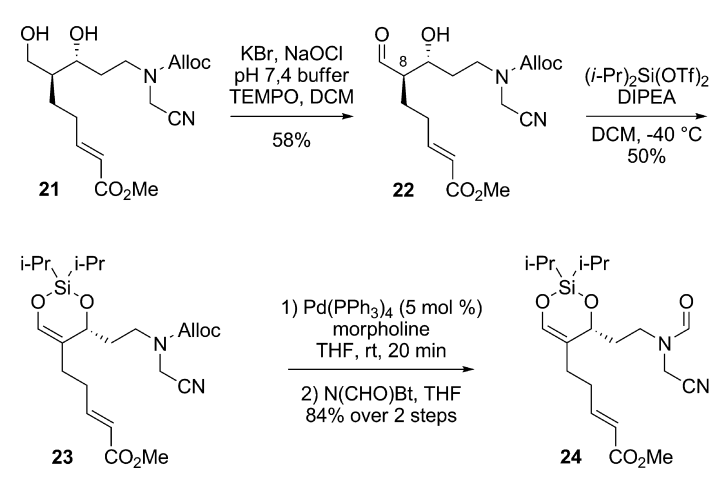

material. ${ }^{16}$ We chose here to use a cyano group instead of the TMS to later generate the azomethine ylide by deprotonation rather than by desilylation as it usually requires milder conditions. ${ }^{6 a, 19}$ The direct reduction of $\mathbf{2 0}$ proved to be more difficult than with model compound $13 \mathbf{a},{ }^{20}$ so we chose to protect the free alcohol with a TMS group, which was removed in the acidic quench of the subsequent reduction reaction, affording the diol $\mathbf{2 1}$ in essentially quantitative yields for these two steps. A chemoselective oxidation of the primary alcohol was then performed using catalytic TEMPO and sodium hypochlorite as co-oxidant. ${ }^{21}$ During this step, we observed an erosion of the diastereomeric ratio probably due to epimerization at the C8 position. However, this was inconsequential because the next step was the enolization to the cyclic silyl enol ether. Formation of the latter was performed using the conditions previously developed (see Scheme 2), albeit in lower yield for reasons that remain unknown. Deallyloxycarbonylation ${ }^{14}$ of 23 followed by immediate formylation using Katrizky reagent ${ }^{22}$ satisfyingly afforded key polycyclization precursor 24 .

Once submitted to amide activation conditions (1.1 equiv of $\mathrm{Tf}_{2} \mathrm{O}$ and 1.1 equiv of DTBMP), the Vilsmeier-Haack cyclization proceeded cleanly and almost instantaneously to form iminium ion $\mathbf{2 5}$ (Scheme 5). When the reaction solution was transferred to a flask containing a refluxing solution of DIPEA (5.0 equiv) in dichloromethane, the cycloaddition reaction also occurred very rapidly. ${ }^{23}$ To our delight, the excess of DIPEA employed in the azomethine ylide generation was sufficient to promote elimination of the cyanide. Two different

Scheme 5. Possible Reaction Pathways to 30 and $31^{25}$<smiles></smiles>

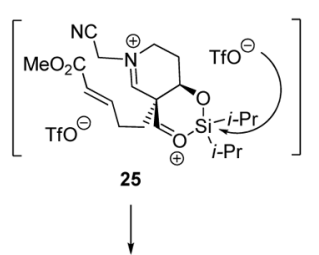

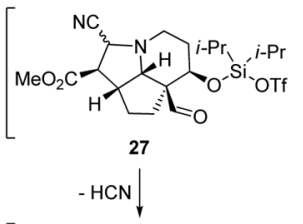

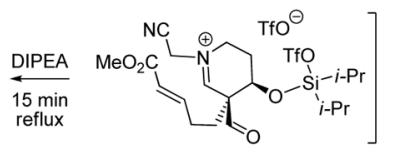
26

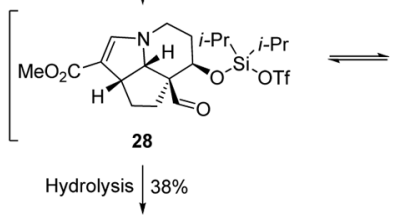
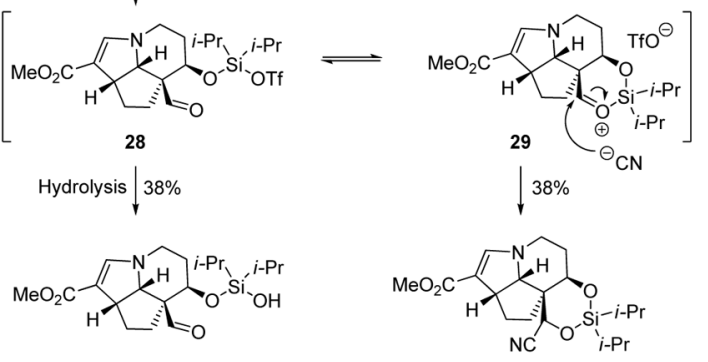

30

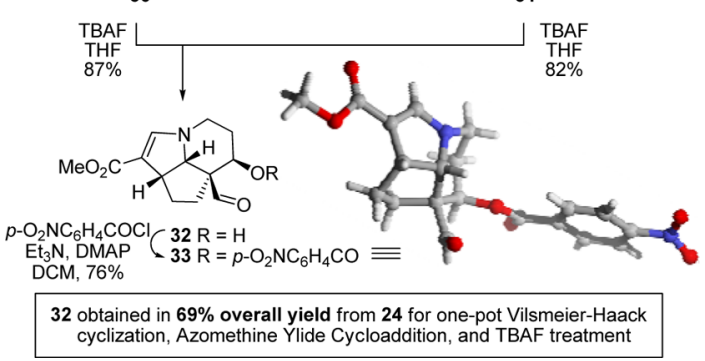


cycloadducts were obtained: the expected tricyclic aldehyde $\mathbf{3 0}$ and the tetracyclic silylated cyanohydrin 31 , in a 1:1 ratio. To explain the formation of these two products, we suspect a partial conversion of silyl triflate $\mathbf{2 8}$ to cyclic oxocarbenium ion $\mathbf{2 9}$. The latter can be trapped by the cyanide generated during the elimination, leading to cyanohydrin 31. Hydrolysis of the remaining silyl triflate $\mathbf{2 8}$ in the aqueous reaction quench would lead to aldehyde 30. Gratifyingly, both 30 and 31 can independently be desilylated using TBAF to generate the tricyclic targeted product 32 in good yields. When the key Vilsmeier-Haack/cycloaddition sequence followed by TBAF treatment was run as a one-pot procedure, an excellent $69 \%$ overall yield of product $\mathbf{3 2}$ was obtained from substrate 24 . Relative configuration was secured by X-ray analysis of crystalline $p$-nitrobenzoyl derivative $33^{24}$ and was consistent with stereochemical analysis presented in Scheme 1 (see 3 to $\mathbf{1}$ ).

In conclusion, we described the preparation and the unprecedented cyclization of a chiral cyclic enol ether onto an activated formamide. The following one-pot intramolecular azomethine ylide generation and 1,3-dipolar cycloaddition generated a functionalized enantiopure tricyclic core obtained in as few as nine linear synthetic steps. This core will be used as a common intermediate toward the synthesis of various members of the calyciphylline B-type alkaloids family. Methods to implement the remaining $\mathrm{C}, \mathrm{D}$, and $\mathrm{F}$ rings are currently under investigation.

\section{ASSOCIATED CONTENT}

\section{S Supporting Information}

The Supporting Information is available free of charge on the ACS Publications website at DOI: 10.1021/acs.orglett.7b01566.

Experimental procedures, characterization data, and copies of the ${ }^{1} \mathrm{H}$ and ${ }^{13} \mathrm{C}$ NMR spectra for all new compounds (PDF)

Single-crystal X-ray data for 33 (CIF)

\section{AUTHOR INFORMATION}

\section{Corresponding Author}

*E-mail: guillaume.belanger@USherbrooke.ca ORCID $\odot$

Guillaume Bélanger: 0000-0002-7454-8760

Notes

The authors declare no competing financial interest.

\section{ACKNOWLEDGMENTS}

The authors thank Dr. Daniel Fortin (U. Sherbrooke) for X-ray diffraction analysis. This research was supported by the Natural Science and Engineering Research Council (NSERC) of Canada and the Université de Sherbrooke.

\section{REFERENCES}

(1) (a) Yamada, R.; Adachi, Y.; Yokoshima, S.; Fukuyama, T. Angew. Chem., Int. Ed. 2016, 55, 6067. (b) Diaba, F.; Martínez-Laporta, A.; Coussanes, G.; Fernández, I.; Bonjoch, J. Tetrahedron 2015, 71, 3642. (c) Wang, W.; Li, G. P.; Wang, S. F.; Shi, Z. F.; Cao, X. P. Chem. - Asian J. 2015, 10, 377. (d) Chattopadhyay, A. K.; Hanessian, S. Chem. Rev. 2017, 117, 4104. (e) Shvartsbart, A.; Smith, A. B. J. Am. Chem. Soc. 2014, 136, 870. (f) Coldham, I.; Burrell, A. J. M.; Guerrand, H. D. S.; Oram, N. Org. Lett. 2011, 13, 1267. (g) Coldham, I.; Watson, L.; Adams, H.; Martin, N. G. J. Org. Chem. 2011, 76, 2360.
(2) (a) Heathcock, C. H.; Davidsen, S. K.; Mills, S.; Sanner, M. A. J. Am. Chem. Soc. 1986, 108, 5650. (b) Heathcock, C. H.; Kath, J. C.; Ruggeri, R. B. J. Org. Chem. 1995, 60, 1120. (c) Heathcock, C. H.; Stafford, J. A.; Clark, D. L. J. Org. Chem. 1992, 57, 2575. (d) Stafford, J. A.; Heathcock, C. H. J. Org. Chem. 1990, 55, 5433.

(3) Morita, H.; Kobayashi, J. I. Org. Lett. 2003, 5, 2895.

(4) (a) Chattopadhyay, A. K.; Berger, G.; Hanessian, S. J. Org. Chem. 2016, 81, 5074. (b) Chattopadhyay, A. K.; Menz, H.; Ly, V. L.; Dorich, S.; Hanessian, S. J. Org. Chem. 2016, 81, 2182.

(5) Chattopadhyay, A. K.; Ly, V. L.; Jakkepally, S.; Berger, G.; Hanessian, S. Angew. Chem., Int. Ed. 2016, 55, 2577.

(6) (a) Boudreault, J.; Lévesque, F.; Bélanger, G. J. Org. Chem. 2016, 81, 9247. (b) Bélanger, G.; Boudreault, J.; Lévesque, F. Org. Lett. 2011, 13, 6204. (c) Hauduc, C.; Bélanger, G. J. Org. Chem. 2017, 82, 4703.

(7) (a) Singh Batra, M.; Brunet, E. Tetrahedron Lett. 1993, 34, 711. (b) Ryu, I.; Murai, S.; Shinonaga, A.; Horiike, T.; Sonoda, N. J. Org. Chem. 1978, 43, 780.

(8) (a) Evans, D. A.; Bartroli, J.; Shih, T. L. J. Am. Chem. Soc. 1981, 103, 2127. (b) Evans, D. A.; Vogel, E.; Nelson, J. V. J. Am. Chem. Soc. 1979, $101,6120$.

(9) Evans, D. A.; Gage, J. R.; Leighton, J. L. J. Am. Chem. Soc. 1992, 114, 9434.

(10) Direct reduction of 10a failed to deliver aldehyde 13a. Transamidation to Weinreb amide 11a then reduction to aldehyde 13a was the best option.

(11) Nahm, S.; Weinreb, S. M. Tetrahedron Lett. 1981, 22, 3815.

(12) For examples of partial reduction of tertiary amides with bis(alkoxy)aluminum hydrides, see: (a) Brown, H. C.; Tsukamoto, A. J. Am. Chem. Soc. 1964, 86, 1089. (b) Cha, J. S.; Lee, J. C.; Lee, H. S.; Lee, S. E.; Kim, J. M.; Kwon, O. O.; Min, S. J. Tetrahedron Lett. 1991, 32, 6903.

(13) Orthogonal deprotection of the allyl carbamate could be effected using $\operatorname{Pd}(0)$ and morpholine as nucleophile (see ref 14). These conditions should not affect the cyclic silyl enol ether or the unsaturated ester.

(14) (a) Lee, H.; Suzuki, M.; Cui, J.; Kozmin, S. J. Org. Chem. 2010, 75, 1756. (b) Bihelovic, F.; Ferjancic, Z. Angew. Chem., Int. Ed. 2016, 55, 2569.

(15) The anti aldol product $\mathbf{1 6}$ was prepared from $8 \mathbf{b}$ and $\mathbf{9}$ using Heathcock's modification of Evans aldol reaction conditions (see ref 16). Procedures and characterization data are found in the Supporting Information.

(16) Walker, M. A.; Heathcock, C. H. J. Org. Chem. 1991, 56, 5747.

(17) Kaliappan, K. P.; Ravikumar, V. J. Org. Chem. 2007, 72, 6116.

(18) Chatterjee, A. K.; Choi, T.-L.; Sanders, D. P.; Grubbs, R. H. J. Am. Chem. Soc. 2003, 125, 11360.

(19) Lévesque, F.; Bélanger, G. Org. Lett. 2008, 10, 4939.

(20) Upon treatment of alcohol 19 with $\mathrm{NaBH}_{4}$, we suspect a conjugate addition of the resulting sodium alkoxide to the unsaturated ester.

(21) Lucio Anelli, P.; Biffi, C.; Montanari, F.; Quici, S. J. Org. Chem. 1987, 52, 2559.

(22) (a) Katritzky, A. R.; Chang, H.-X.; Yang, B. Synthesis 1995, 1995, 503. (b) Pasqua, A. E.; Matheson, M.; Sewell, A. L.; Marquez, R. Org. Process Res. Dev. 2011, 15, 467.

(23) Longer reaction times for that step provided the same products 30 and 31 albeit in a lower combined yield (50\%).

(24) An ORTEP representation of 33 is found in the Supporting Information. Crystallographic data for this compound have been deposited with the Cambridge Crystallographic Data Centre (CCDC no. 1548926). Coordinates can be obtained at http://www.ccdc.cam.ac. uk/deposit.

(25) For representation of X-ray structure, see: CYLview, 1.0b; Legault, C. Y., Université de Sherbrooke, 2009 (http://www.cylview.org). 